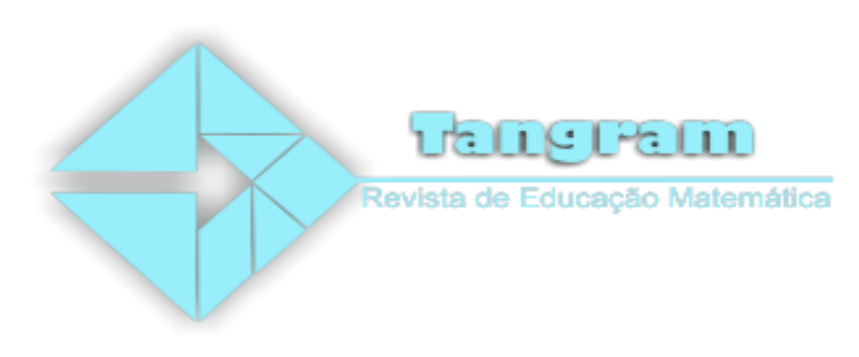

\title{
Uma investigação com diálogos-com-mídias em projetos de modelagem
}

\section{A research with dialogue-with-media in modelling projects}

\author{
Neil da Rocha Canedo Jr. ${ }^{1}$ \\ Marco Aurélio Kistemann Jr. ${ }^{2}$
}

\begin{abstract}
Resumo: Este artigo apresenta uma investigação de natureza qualitativa, desenvolvida a partir de resultados de pesquisas acadêmicas realizadas pelo primeiro autor. O objetivo desse artigo é explicitar algumas interações comunicativas estabelecidas entre um professor de Matemática e alunos do sexto ano do Ensino Fundamental de uma escola pública, ao longo do desenvolvimento de um Projeto de Modelagem envolvendo Seres-humanos-com-mídias e internet. $\mathrm{O}$ foco central da pesquisa foram os diálogos durante o desenvolvimento de um projeto de Modelagem. A análise qualitativa aqui apresentada considera três episódios analíticos no qual internet e ações de mídia foram examinadas, em relação aos processos comunicativos entre os alunos e o professor. O referencial teórico fundamentouse nesses processos, reunindo duas perspectivas teóricas e promovendo o encontro entre a noção de diálogo, apresentada no âmbito das preocupações da Educação Matemática Crítica. A visão do conhecimento assumido na construção humanos-com-mídia foi considerada durante todas as etapas da pesquisa. Destacamos que os principais resultados foram o desenvolvimento da autonomia discente com apoio da mediação docente, bem como dar voz aos alunos para que os mesmos se constituíssem como investigadores num cenário para investigação envolvendo mídias, transcendendo o paradigma do exercício. Buscamos aproximar a visão de conhecimento assumida pelo construto teórico sereshumanos-com-mídias, na qual as mídias adquirem poder de ação nos coletivos que produzem conhecimento, com a noção de aprendizagem como diálogo, presente na perspectiva da Educação Matemática Crítica.
\end{abstract}

Palavras-chave: Seres-humanos-com-mídias. Projetos de Modelagem. Diálogo-com-mídias.

Abstract: This article presents an investigation of a qualitative nature, developed from the results of academic research carried out by the first author. The purpose of this article is to explain some communicative interactions established between a Mathematics teacher and students of the sixth year of Elementary School in a public school, along the development of a Modeling Project involving human beings-with-media and the internet. The central focus of the research was the dialogues during the

\footnotetext{
${ }^{1}$ Mestre em Educação Matemática (UFJF) e Doutorando em Educação Matemática (Unes-Rio Claro-SP) - email: neilcanedo@gmail.com

${ }_{2}^{2}$ Doutor em Educação Matemática (Unesp-Rio Claro-SP) e Líder do Grupo Pesquisa de Ponta (UFJF) - email: marco.kistemann@ufff.edu.br
}

Tangram - Revista de Educação Matemática, Dourados - MS - v.1 n. 1, pp. 18 - 36 (2018) 
development of a Modeling project. The qualitative analysis presented here considers three analytical episodes in which the internet and media actions were examined in relation to the communicative processes between the students and the teacher. The theoretical framework was based on these processes, bringing together two theoretical perspectives and promoting the encounter between the notion of dialogue, presented within the scope of the Mathematical Critical Education concerns. The view of the knowledge assumed in human-media construction was considered during all stages of the research. We emphasize that the main results were the development of student autonomy with the support of the teacher mediation, as well as giving the students the voice to be constituted as researchers in a scenario for research involving media, transcending the exercise paradigm. We seek to approximate the view of knowledge assumed by the human beings-with-media theoretical construct, in which the media acquire power of action in the collectives that produce knowledge, with the notion of learning as dialogue, present in the perspective of Critical Mathematical Education.

Keywords: Humans-with-media. Modeling Projects. Dialogue-with-media.

\section{Introdução}

O Objetivo desse artigo é explicitar algumas as interações comunicativas estabelecidas entre um professor de Matemática e alunos do sexto ano do Ensino Fundamental de uma escola pública, ao longo do desenvolvimento de um Projeto de Modelagem envolvendo Sereshumanos-com-mídias e internet. Busca ainda busca-se expandir a noção de diálogo em um cenário de investigação com alunos do ensino fundamental mediados por um professor de Matemática. No âmbito dessas considerações, objetivamos investigar também o poder de ação das mídias nos coletivos de humanos e mídias que produzem conhecimento (Borba; Villarreal, 2005).

A investigação realizada e apresentada aqui constitue-se como ações que foram efetuadas pelo primeiro autor, orientadas pelo segundo autor, visto que ambos compõem um grupo de pesquisa em Modelagem Matemática na sala de aula. Nesse sentido, ainda objetivamos aprofundar o entendimento sobre os Projetos de Modelagem e as aproximações dessa abordagem pedagógica com a noção de diálogo, à luz de algumas das preocupações da Educação Matemática Crítica, bem como construir a noção de diálogo-com-mídias por meio dos episódios apresentados.

O que acontece quando professores de Matemática de ensino fundamental, médio ou superior decidem agregar às suas práticas, cenários envolvendo a Modelagem Matemática? O que ocorre quando a voz do professor dialoga com as vozes dos estudantes em projetos com temáticas que denominamos Projetos de Modelagem? Como os estudantes se comportam quando são convidados a vivenciar cenários distintos dos propiciados pelas aulas expositivas,

Tangram - Revista de Educação Matemática, Dourados - MS - v.1 n. 1, pp. 18 - 36 (2018) 
utilizando a internet e tecnologias? Como se dá a comunicação quando professor, estudantes e a internet estão interagindo para conhecer temas matemáticos ou relacionados à Matemática? Essas são questões que nos guiaram em uma pesquisa de mestrado e já estavam presentes em nossos questionamentos e práticas pedagógicas, antes e após o mestrado.

Os educadores matemáticos Roberto Ribeiro Baldino e Romulo Campos Lins, em suas aulas, proferiam a seguinte citação: "Matemática se aprende falando e se ensina ouvindo". Estendemos essa crença complementando que falar, ouvir e fazer devem compor o quadro de produção de conhecimentos matemáticos. Essa citação tem, nos últimos dez anos, orientado nossas ações pedagógicas e reflexões na sala de aula de Matemática.

Essa citação, de certa forma, convidou-nos a refletir e mudar a forma de apresentar a Matemática aos nossos alunos, uma vez que, que apresentávamos a eles já não mais atraia a atenção dos mesmos, em um cenário social e escolar, grandemente marcado por tecnologias, em geral, não utilizadas pelos professores, mas presente, por exemplo, nas mãos dos alunos, que possuem e dominam o uso de aparelhos de telefonia celular móvel, com acesso à internet e equipados com aplicativos diversos.

Como resultado dessas reflexões, procuramos praticar em nossas salas de aula abordagens pedagógicas de cunho investigativo e exploratório, dentre as quais destacamos a Modelagem. A Modelagem é uma prática letiva em Educação Matemática, vinculada a uma linha de pesquisa com produção relevante nos cenários brasileiro e internacional (Araújo, 2010). Assim, emerge uma multiplicidade de definições e concepções de Modelagem, o que nos obriga a esclarecer do que exatamente estamos falando, quando trabalhamos com Modelagem na Educação Matemática.

Nesse sentido, a nossa concepção de Modelagem configura-se em uma abordagem pedagógica na qual os alunos são convidados a eleger um tema, a partir do qual dialogam, problematizam e investigam por meio da Matemática e sob a orientação do professor. Essa perspectiva de Modelagem se alinha à noção de Projetos de Modelagem apresentada em Araújo (2002), a qual se inspira nos Trabalhos com Projetos, comuns na Educação Matemática dinamarquesa, os quais se desenvolvem de acordo com as preocupações da Educação Matemática Crítica, entre as quais o diálogo e a aprendizagem (Alrø; Skovsmose, 2010; Skovsmose, 2000; Skovsmose, 2007).

As nossas concepções de Modelagem se amalgamam com a visão do conhecimento sobre como algo que não é suscetível de ser descoberto ou transmitido, se produz nas interações 
entre os seres-humanos e as mídias (oralidade, escrita e informática) e com as tecnologias da inteligência que participam como atores nos coletivos pensantes de seres-humanos-com-mídias que produzem conhecimento (Borba; Villareal, 2005).

Diante das concepções de conhecimento e Modelagem assumidas por nós, esse artigo apresenta uma análise qualitativa (Bogdan; Biklen, 1994), constituída a partir dos desdobramentos da pesquisa acadêmica do primeiro autor, e que parceria com o segundo autor, tendo como lócus de inquérito as interações comunicativas estabelecidas entre professor e alunos do sexto ano do Ensino Fundamental, ao longo do desenvolvimento de um Projeto de Modelagem. No decorrer dessa análise, procuramos construir e apresentar a noção de diálogocom-mídias, elaborada em termos de uma expansão da noção de diálogo, apresentada em Alrø e Skovsmose (2010), no sentido de incluir a ação das mídias nesses processos comunicativos.

\section{Educação Matemática Crítica: Projetos de Modelagem e Aprendizagem como Diálogo}

A noção de Projetos de Modelagem se refere a uma maneira de conduzir as atividades de Modelagem na sala de aula, levando-se em consideração uma das preocupações da Educação Matemática Crítica, qual seja o Diálogo e a Aprendizagem. Nesse viés, a Modelagem é assumida como uma abordagem pedagógica na qual os alunos, mediados pelo professor, elegem um tema para que possam problematizá-lo e investigá-lo por meio da Matemática. Essa perspectiva de Modelagem se aproxima dos Trabalhos com Projetos, presentes nas salas de aulas da Dinamarca, da maneira em que são apresentados por Skovsmose (2000) (c. f. Alrø; Skovsmose, 2010; Skovsmose, 2007).

Entendemos que esse modo de conceber e praticar a Modelagem na sala de aula, em que os alunos problematizam e investigam, a partir de um tema eleito em vistas dos seus interesses, promove o que Alrø e Skovsmose (2010, p. 33) denominam de "abertura desde o começo". Nesse sentido, os trabalhos com Modelagem desenvolvidos na perspectiva dos Projetos de Modelagem estão em sintonia com a preocupação da Educação Matemática Crítica, em superar as limitações das práticas tradicionais de sala de aula, em geral, pautadas no paradigma do exercício, pois se direcionam para a utilização de abordagens investigativas que possam favorecer a existência dos cenários para investigação (Skovsmose, 2000).

Além disso, ao conferir aos alunos o poder de escolha dos temas de seus Projetos de Modelagem, defendemos que essa prática pedagógica contribui para uma Educação Matemática 
preocupada com o desenvolvimento da autonomia discente com apoio da mediação docente. Enfatizamos que essa preocupação com a autonomia é influenciada pelos ideais da educação libertadora, proposta por Paulo Freire.

Tanto nos trabalhos com Projetos que são desenvolvidos nas salas de aula da Dinamarca, como na perspectiva do Projeto de Modelagem que norteou a atividade de Modelagem à qual esse artigo se refere, promove-se uma abordagem não internalista da Matemática, ou seja, não entendemos os conhecimentos matemáticos, como conhecimentos que somente podem ser construídos num ambiente escolar e lá ficarem restritos para serem avaliados.

Em termos mais amplos, uma visão internalista concebe que a Matemática pela Matemática é suficiente para a aprendizagem, argumento que discordamos entendendo que podem ser construídos conhecimentos matemáticos numa diversidade cultural, social e histórica com a utilização da Matemática. Nessa visão internalista o paradigma do exercício tem destaque central e traduz-se numa concepção de que a Matemática tem sua essência no âmbito escolar.

Uma visão distinta da internalista e que praticamos, crê que a Matemática, em suas diversas concepções, serve para resolver problemas com uma multiplicidade de representações e respostas que auxiliem os estudantes a utilizarem as Matemáticas e as tecnologias disponíveis para solucionar problemas escolares e do âmbito social. Assim,

As referências são reais, tornando possível aos alunos produzirem significados
para as atividades (e não somente conceitos). [...] Isso quer dizer que são
eliminadas as autoridades que exercem seu poder no paradigma do exercício.
O pressuposto de que há uma, e somente uma resposta correta não mais faz
sentido. Livros didáticos podem descansar seguramente no canto da sala de
aula à medida que um projeto desse tipo é desenvolvido. O professor tem o
papel de orientar. [...] A reflexão crítica sobre matemática e modelagem
matemática ganha um novo significado (Skovsmose, 2000, p. 81).

Ao apontarem as implicações de uma Educação Matemática pautada no paradigma do exercício, Alrø e Skovsmose (2010) destacam que essa tradição influencia os padrões de comunicação que se estabelecem na sala de aula. Segundo esses autores, o paradigma do exercício é sustentado por acordos implícitos, mas bem definidos, entre alunos e professor, dentre os quais se incluem a existência e aceitação de uma única resposta correta para os exercícios, além de uma maneira pré-estabelecida de se obter tal resposta. De acordo com a nossa experiência, ao eleger uma visão internalista da Matemática e reificar o paradigma do exercício, o professor limita as diversas formas de comunicação que poderiam ocorrer em sua 
sala de aula. Nesse caso, o professor torna-se figura central do processo educativo e os alunos apenas meros repetidores de tarefas que serão avaliadas em provas.

Nesse âmbito, os acordos padronizam as comunicações estabelecidas em sala de aula, em termos de um jogo de perguntas e respostas, no qual o professor faz a pergunta antevendo a resposta do aluno. Entendemos que a ênfase em ações que reifiquem cenários de instrução, pautados somente no paradigma do exercício, contribuem para o monólogo na sala de aula com a voz docente predominando esse cenário e reforçando uma visão internalista da Matemática. Nossa opção em sair da zona do conforto e promover o diálogo em cenários para investigação, envolvendo mídias, busca transcender as práticas correntes do paradigma do exercício que tem seu espaço, mas não deve predominar nas ações em sala de aula como único meio de promoção da aprendizagem matemática.

Diferente do que acontece na tradição da repetição de exercícios, na atmosfera dos cenários para investigação outras possiblidades comunicativas se abrem nas interações entre alunos e professor. Assim, “(...) há diferentes aspectos envolvidos no processo de mudança do paradigma do exercício para os cenários para investigação. Os padrões de comunicação podem mudar e abrir-se para novos tipos de cooperação e para novas formas de aprendizagem" (Alrø; Skovsmose, 2010, p. 58).

Nesses cenários que promovemos em nossas práticas,

(...) os alunos podem formular questões e planejar linhas de investigação de forma diversificada. Eles podem participar do processo de investigação. Num cenário para investigação a fala "O que acontece se...?" deixa de pertencer apenas ao professor e passa a poder ser dita pelo aluno também. E outra fala do professor, "Por que é dessa forma...?", pode desencadear a fala do aluno "Sim, por que é dessa forma...?" (Alrø; Skovsmose, 2010, p. 55-56 - grifos dos autores).

Desse modo, os cenários para investigação são abertos aos interesses, escolhas e problematizações propostas pelos alunos. Isso reforça as nossas considerações a respeito da sintonia entre Projetos de Modelagem e os Cenários para Investigação. Contudo, Alrø e Skovsmose (2010) procuram deixar muito claro que não é qualquer forma de comunicação que pode ser considerada um diálogo. O jogo de perguntas, respostas e adivinhações, no qual as comunicações se padronizam na tradição do paradigma do exercício, por exemplo, distancia-se da ideia de aprendizagem como diálogo. O conceito de diálogo envolve uma multiplicidade de desdobramentos teóricos que nos obrigam a especificar o que estamos considerando como diálogo, bem como pretendemos relacionar diálogo e aprendizagem.

Tangram - Revista de Educação Matemática, Dourados - MS - v.1 n. 1, pp. 18 - 36 (2018) 
Nesse sentido, Alrø e Skovsmose (2010, p. 123) apresentam a noção de diálogo como aprendizagem a partir de três características fundamentais: “(1) realizar uma investigação; (2) correr riscos e (3) promover a igualdade".

Exploremos um pouco mais essas características que tê guado nossas ações como professores:

(1) Realizar uma investigação significa deixar-se levar pelo diálogo, a curiosidade e o desejo de aprender. No caso dos Projetos de Modelagem, essa investigação deve partir do interesse dos alunos pelo tema escolhido por eles, de maneira que a Matemática se apresenta tanto como um meio pelo qual o tema é investigado, como objeto de reflexão da própria investigação. Alrø e Skovsmose (2010) apontam que realizar uma investigação inclui estar disposto a explorar as perspectivas dos participantes, abrir mão das próprias perspectivas e construir novas perspectivas, dentro de um processo de moldagem recíproca dos pontos de vistas em direção às novas possibilidades de aprendizagens.

(2) Correr riscos se relaciona com a imprevisibilidade a respeito das direções que os processos dialógicos podem tomar, bem como as possibilidades de aprendizagem que os participantes podem vivenciar. Essa imprevisibilidade se contrapõe ao jogo de perguntas e respostas que padroniza as comunicações, na tradição da sala de aula de Matemática, ao excluir a possibilidade de antever a resposta do aluno. "Uma questão essencial é, como, em tal situação, um professor pode agir como um supervisor, cuidando para que os alunos não se percam quando enfrentarem a situação de risco, sem, contudo, eliminar o risco por completo" (Alrø; Skovsmose, 2010, p. 129).

(3) Promover a igualdade se relaciona com manter o respeito pelos pontos de vistas defendidos pelos outros participantes de um cenário. Participar de um diálogo não pode ser algo imposto aos participantes, como uma atividade compulsória, da mesma forma que não faz sentido tomar parte em um diálogo, em troca de uma espécie de recompensa, a nota bimestral, por exemplo. Um diálogo também não pode degenerar em uma discussão, na qual os envolvidos buscam defender suas perspectivas e opiniões, no intuito de impô-las aos demais. E essas considerações a respeito da igualdade nos remetem aos diferentes papéis desempenhados por alunos e professor na sala de aula. (Alrø; Skovsmose, 2010, p. 130)

Nesse sentido, Alrø e Skovsmose (2010) se preocupam em diferenciar a igualdade (equality), que deve ser mantida entre os participantes do diálogo, da uniformidade (sameness), que não faz sentido nas interrelações entre alunos e professor. "Professor e aluno são posições 
diferentes, profissionalmente falando; do contrário, não haveria ensino. Contudo, eles podem ser igualitários no nível das relações e comunicações interpessoais" (Alrø; Skovsmose, 2010, p. 131). Acrescentamos que as atividades de Modelagem desenvolvidas na perspectiva dos nossos Projetos de Modelagem, com os alunos elegendo um tema a ser investigado, configuram-se como um passo na direção de correr riscos, promover a igualdade e a continuidade de diálogo.

Contudo, as intenções desse artigo se dirigem à possibilidade de considerar a participação das mídias nesses diálogos. Esse objetivo está fortemente relacionado à visão de conhecimento que assumimos na perspectiva do construto teórico Seres-humanos-com-mídias (Borba; Villarreal, 2005). Acrescentamos, ainda, que essa visão de conhecimento está em ressonância com nossas opções metodológicas.

\section{Seres-humanos-com-mídias: nossa visão epistemológica}

Da perspectiva do construto Seres-humanos-com-mídias (Borba; Villarreal, 2005), o conhecimento é tido como algo que não pode ser transmitido ou descoberto, mas que se produz nas interrelações que ocorrem no âmbito de um coletivo pensante de seres-humanos-commídias.

Nesses coletivos, as mídias (oralidade, escrita e informática) são vistas como tecnologias da inteligência que participam como atores nos processos de produção de conhecimento, de forma que o conhecimento produzido, por exemplo, na presença de lápis e papel, não é pior nem melhor, mas, qualitativamente, diferente daquele produzido na presença de computadores conectados à internet.

Essa visão de conhecimento expande o sujeito epistêmico na direção de torná-lo o próprio coletivo pensante de seres-humanos-com-mídias que produz conhecimento. Nesse sentido, de acordo com Skovsmose (2007, p. 229),

podemos ver o sujeito que aprende como sendo um grupo co-operando, e esse grupo pode "incluir" ferramentas (ou tecnologia, ou mídia) como uma parte integral. Aprendizagem pode significar co-operação com ferramentas. Podemos ver o sujeito da aprendizagem como parte de uma rede, que inclui seres humanos e elementos não-humanos. O sujeito da aprendizagem pode então ser definido em termos de relacionamento interpessoal, bem como em termos de relações humano-tecnológicas. O sujeito da aprendizagem torna-se uma propriedade relacional. 
Nesse mesmo viés, Alrø e Skovsmose (2010, p. 130) destacam que a "noção de sereshumanos-com-mídias desempenha papel importante no entendimento da noção de diálogo" e que "todo processo de aprendizagem envolve algum tipo de 'instrumento'; pode ser papel e caneta ou tecnologias de informação e comunicação".

No âmbito dessas considerações, retomamos os objetivos desse artigo, os quais se voltam para expandir a noção de diálogo (Alrø; Skovsmose, 2010) na direção de incluir o poder de ação das mídias nos coletivos de humanos e mídias que produzem conhecimento (Borba; Villarreal, 2005).

Nesse sentido, da perspectiva da noção de diálogos-com-mídias que buscamos construir, a ação das mídias nos processos coletivos considera as intenções e pontos de vistas desses atores não humanos em suas interrelações com as intencionalidades e perspectivas dos sujeitos humanos, no caso alunos e professor, em vistas das características fundamentais do diálogo: realizar uma investigação, correr riscos e promover a igualdade. Mas, como considerar as intenções e pontos de vistas desses atores não humanos nos processos comunicativos que se desenvolvem na sala de aula?

\section{Opções Metodológicas}

No sentido de cumprir os objetivos desse artigo, tomamos como pano de fundo a nossa leitura das interações de um grupo de alunos do sexto ano do Ensino Fundamental (Sara, Rafa e Tevez). A seleção desses três sujeitos foi feita utilizando-se o critério de quem participava mais e dialogava com o professor-pesquisador no desenvolvimento de um Projeto de Modelagem.

Nossa leitura considerou três episódios ( $1^{\circ}$ : Iniciando uma investigação; $2^{\circ}$ : Do autoritarismo burocrático ao digital; e $3^{\circ}$ : Dialogando com a mídia internet). Esses episódios ocorreram ao longo dos encontros destinados ao desenvolvimento do trabalho de campo da pesquisa acadêmica, conduzido pelo primeiro autor, e foram extraídos do corpo de dados dessa mesma pesquisa, na forma de transcrições das gravações, em áudio, das conversas estabelecidas entre os alunos e o professor.

Ao longo da leitura que tecemos desses episódios comunicativos, procuramos construir a noção de diálogo-com-mídias, em termos da ação da mídia internet nesse coletivo de sereshumanos-com-mídias, bem como explicitar a noção de diálogo apresentada anteriormente. 
Ressaltamos que, na transcrição desses processos comunicativos, as reticências simples (...) significam intenção de continuidade nas falas dos sujeitos e as reticências entre colchetes ([...]) denotam cortes em trechos das falas, na intenção de dar sentido sequencial às conversas. Além disso, procuramos transcrever essas conversações respeitando a maneira como os sujeitos (alunos e professor) enunciavam suas falas.

A opção pelo paradigma qualitativo de pesquisa (Bogdan; Biklen, 1994) está em consonância com nossa visão epistemológica e com os próprios objetivos da pesquisa. Como tomamos por meta ler os processos comunicativos, a partir das características do diálogo e da ação das mídias nesses processos, fez sentido privilegiar uma análise dos dados coletados em seu ambiente natural, no caso, os Projetos de Modelagem desenvolvidos pelos alunos na sala de aula de Matemática.

\section{A noção de diálogos-com-mídias em um projeto de modelagem}

$\mathrm{Na}$ sequência, apresentamos a análise dos três episódios elencados a partir da, e buscando elaborar a, noção de diálogo-com-mídias. Como veremos, essa noção implica em uma metáfora pela qual os alunos conversam com a mídia internet, ao longo do desenvolvimento de um Projeto de Modelagem, para o qual elegeram como tema: "Os custos das viagens aéreas e rodoviárias".

Essa conversa metafórica entre seres-humanos e mídias é constituída por falas atribuídas à internet, como explicitaremos mais à frente que se intercalam a alguns trechos transcritos das falas pronunciadas, de fato, pelos atores humanos, no transcorrer dos episódios analíticos.

\section{- $1^{0}$ episódio: Iniciando uma investigação}

Logo no primeiro encontro, os alunos elegeram o tema viagem para o Projeto de Modelagem que desenvolveriam. Após a escolha dessa temática, alunos e professor iniciam uma conversação a respeito dos valores das passagens aéreas e rodoviárias.

Sara: Avião. Sabia que avião não é caro? Avião é mais barato que ônibus. [...] Igual... A minha tia foi pegar o avião sexta-feira. De Juiz de Fora pra São Paulo. Vinte e cinco.

Professor: Então você tá querendo me dizer que pode ser que avião fique mais barato?

Sara: É. Avião é mais barato mesmo.

Tangram - Revista de Educação Matemática, Dourados - MS - v.1 n. 1, pp. 18 - 36 (2018) 
Rafa: Depende pra onde você vai também, né? Tem de primeira classe, de primeira classe já é "biro-biro" a mais. [...] A minha tia foi viajar pra não sei aonde. Ela é tia da minha amiga. Foi viajar pra não sei aonde, o negócio lá de segunda classe é vinte e cinco, e o de primeira classe já é...

Teves: Já é cinquenta.

Rafa: É, cinquenta... Cem pra lá...

Sara: É, primeira classe é caro... (XXXXXX XX, 2014, p. 136).

Retornando à ideia de aprendizagem como diálogo, inferimos por esses diálogos iniciais que os alunos tiveram a intenção de realizar uma investigação a respeito do tema por eles eleito. Porém, é preciso lembrar que uma investigação, pautada no diálogo, prescinde da disposição em "abandonar a comodidade da certeza e deixar-se levar pela curiosidade" (Alrø; Skovsmose, 2010, p. 123).

Nesse sentido, as falas de Sara, Rafa e Teves sugerem que a intenção dos alunos em realizar a investigação precisa superar a atitude afirmativa que esses sujeitos estão assumindo, até aqui, a respeito dos valores das passagens. Sara afirma e sustenta, mesmo diante do questionamento do professor, a ideia de que a passagem aérea é sempre mais cara que a rodoviária. Rafa, por sua vez, procura introduzir mais variáveis à problemática, ao mencionar a opção pela primeira ou segunda classe.

As considerações apontadas por Rafa e pelo professor poderiam ser levadas em conta por Sara, no sentido de um convite a rever os seus pontos de vista e, assim, correr o risco de deixar de lado suas convicções a respeito do menor valor da passagem aérea. Porém, Sara não abandona sua postura afirmativa e a investigação permanece, até aqui, no horizonte das possibilidades.

Por outro lado, é relevante considerarmos que o diálogo entre esses alunos e o professor a respeito dos valores das passagens, embora não se configure, ainda, plenamente como uma aprendizagem por meio do diálogo, supera em certos aspectos os padrões de comunicação presentes na tradição da Educação Matemática no âmbito escolar. Não há, por exemplo, um jogo de perguntas e respostas no qual o professor procura antever a resposta do aluno e termina por dar, sempre, a última palavra.

Mas, o que podemos dizer sobre a participação das mídias nessa interação entre alunos e professor? Na verdade, o que temos é uma comunicação entre seres-humanos-com-oralidade que não configura, pelo menos até aqui, um diálogo-com-mídias, no sentido em que vislumbramos essa noção.

Tangram - Revista de Educação Matemática, Dourados - MS - v.1 n. 1, pp. 18 - 36 (2018) 


\section{- $2^{\circ}$ episódio: Do autoritarismo burocrático ao digital}

No intuito de prosseguir com o desenvolvimento do Projeto de Modelagem, na direção de uma atitude investigativa dos alunos, o professor mediador pesquisou na internet por preços de passagens aéreas e rodoviárias, com origem e destino diversos, para que os alunos pudessem comparar os valores dessas passagens.

É importante destacar que o professor realizou essa pesquisa de preços na internet, por si, entregando o resultado da busca aos alunos na forma de folhas impressas. Uma dessas folhas continha os valores das passagens aéreas entre diferentes origens e destinos, enquanto a outra trazia os valores das passagens rodoviárias, também para origens e destinos vários.

Embora essas listas de preços configurem folhas impressas (mídias escritas), entendemos que, o fato dos valores terem sido obtidos por meio da internet, faz com que essa mídia esteja presente, de certa maneira, no coletivo de seres-humanos-com-mídias que desenvolve o Projeto de Modelagem em questão.

O trecho do diálogo seguinte diz respeito às interações entre os alunos e o professor, mediante consultas nas mencionadas listas de preços.

Sara: Vou mentir não, de ônibus é mais cara.

Rafa: Depende pra onde a gente tá indo [...].

Sara: Brasília ao Rio de Janeiro: cento e sessenta, de avião. Brasília, de ônibus, assim, ao Rio, é cento e setenta e nove [...].

Teves: De São Paulo ao Rio de Janeiro, setenta e oito reais [valor da passagem aérea]. [...] Oitenta e nove [valor da passagem rodoviária.

Sara: De avião agora, quer ver? Salvador ao Rio de Janeiro... Cento e nove. Tá vendo como a passagem de avião é mais barata que de ônibus (XXXXXX XX, p. 149-150).

A consulta realizada pelos alunos nas listas de preços apresentadas pelo professor, com valores obtidos na internet, fez reforçar o ponto de vista sustentado pelos alunos, na atitude afirmativa, a respeito do preço da passagem aérea ser, sempre menor que o da passagem rodoviária. Nesse sentido, a participação da mídia internet no coletivo de seres-humanos-commídias, por meio dos valores apresentados nas listas de preços, não contribuiu no sentido de fazer com que os alunos abrissem mão dos seus pontos de vista. Em vez disso, fez reforçar tal ponto de vista.

A seguir, apresentamos um diálogo entre os alunos, o professor e a internet, que busca ilustrar as interações comunicativas que acontecem entre humanos e mídias, no âmbito desse 
coletivo pensante. Esse diálogo, na qual a voz da internet aparece grifada em itálico, constitui uma metáfora, por meio da qual pretendemos apresentar ideia da ação das mídias nas comunicações entre seres-humanos-com-mídias no coletivo, por meio da noção de diálogoscom-mídias. Nesse diálogo (imaginário) a Internet se faz presente, influenciando a tomada de decisão e corroborando com as crenças dos alunos.

Professor: Então vocês estão querendo dizer que pode ser que avião fique mais barato? Alunos: É. Avião é sempre mais barato mesmo.

Internet: Muito bem meninos! Vocês acertaram!

Percebe-se que os padrões da comunicação que, tradicionalmente, se estabelecem na sala de aula estão presentes, embora de uma maneira qualitativamente nova, no metafórico trecho de conversa acima. Lembramos que na tradição das aulas de Matemática, em que o autoritarismo burocrático está presente, as comunicações podem ser sintetizadas num modelo formatado, ou seja, “(...) o professor faz a pergunta, o aluno responde, e o professor avalia a resposta" (Alrø; Skovsmose, 2010, p. 27).

Se considerarmos a fala da internet no diálogo (imaginário) apresentado anteriormente, percebemos que coube à internet o papel de formatar o diálogo entre alunos e professor, ao confirmar a atitude afirmativa dos alunos em relação à comparação dos valores das passagens. É como se a presença dessa mídia informática reduzisse o iminente diálogo, a um padrão de conversação pautado no jogo de perguntas e respostas, com a presença da internet configurando uma espécie de autoritarismo digital, similar ao autoritarismo burocrático que permeia as relações e interações entre alunos, professor e livro didático na tradição da sala de aula de Matemática (c.f. Alrø; Skovsmose, 2010).

Contudo, a partir de nossas concepções de conhecimento e Modelagem, defendemos a postura epistemológica de que os Projetos de Modelagem podem dar suporte a uma aprendizagem construída a partir do diálogo, na qual está presente a possibilidade de dialogar com as mídias no âmbito de um coletivo de seres-humanos-com-mídias, conforme nos revela o episódio 3, a seguir. Como procuraremos mostrar, a seguir, a análise do terceiro episódio converge para isso.

\section{- $3^{\circ}$ episódio: Dialogando com a mídia internet}

Tangram - Revista de Educação Matemática, Dourados - MS - v.1 n. 1, pp. 18 - 36 (2018) 
Com vistas a permitir aos alunos um avanço na compreensão das relações entre os valores das passagens aéreas e rodoviárias, o professor sugeriu-lhes que buscassem, eles próprios, e por meio da internet, pelos valores das passagens aéreas e rodoviárias para origens e destinos diversos. Nessa busca, os alunos simulavam a compra dessas passagens em sites da web, nos quais elas eram oferecidas à venda.

A organização e o tratamento desses dados por meio de tabelas comparativas levaram os alunos a compreenderem que a data da compra é uma variável que precisa ser considerada nessa comparação de preços. O trecho de conversa a seguir, diz respeito a um diálogo ocorrido logo após o tratamento comparativo dos valores dessas passagens, no qual a data da compra foi levada em conta.

Professor: O que que você descobriu sobre a data e o preço da passagem de avião?

Sara: Que o valor às vezes... [...] Ele abaixa... Tipo, tá trezentos e cinquenta. Aí abaixa pra duzentos.

Professor: Mas o que que faz abaixar?

Sara: A data.

Professor: Como assim?

Rafa: É porque quanto mais antes você compra, mais barato é. Quanto mais aproximadamente é a... O dia da viagem, mais caro é.

Sara: Ou se você demora... Ou se você demora a comprar, a passagem vai aumentando, aumentando, aumentando, aumentando...

Rafa: Quanto mais perto da viagem

Professor: Então, vocês estão falando sobre a passagem de avião [...].

Rafa: Os preços de ônibus é tudo...

Professor: Os preços de ônibus é o que?

Rafa: Oi? É tudo mais ou menos o mesmo preço...

Sara: Os preços de ônibus é tudo baixo.

Rafa: Não muda tanto igual o avião não [...].

Professor: Então esse valor fica fixo, independente de quando se compra?

Sara: E de ônibus não abaixa, nem por causa de data nem nada. Só a de avião mesmo que abaixa (XXXXXX XX, 2014, p. 208-209).

As falas dos alunos nesse diálogo com o professor sugerem que a comparação dos preços, a partir das buscas na internet, levou esses alunos a reconsiderarem seus pontos de vistas, a respeito do valor da passagem aérea ser sempre menor que o da passagem rodoviária, uma vez que o valor da primeira tende a mudar em relação à antecipação da compra. Mas, de que forma a internet participa desse diálogo entre alunos e professor? Vamos dar sequência à metáfora do diálogo (imaginário) para que se possa ouvir a voz da mídia internet: 
Internet: $O$ que acontece se considerarmos a data da compra na comparação entre os preços das passagens?

Alunos: É porque quanto mais antes você compra, mais barato é. Ou se você demora a comprar, a passagem vai aumentando, aumentando, aumentando, aumentando...

Professor: Então, vocês estão falando sobre a passagem de avião.

Alunos: Os preços de ônibus é tudo... É tudo mais ou menos o mesmo preço... E de ônibus não abaixa, nem por causa de data nem nada. Só a de avião mesmo que abaixa.

A fala atribuída à internet nesse diálogo-com-mídias configura um convite à problematização e à investigação que foi aceito pelos alunos. E isso os levou a reconsiderarem seus pontos de vistas a respeito do valor das passagens aéreas e rodoviárias.

Entendemos que a metáfora do diálogo-com-mídias, na qual as mídias, literalmente, ganham voz, pode nos ajudar a compreender a ação dos atores não humanos nos diálogos que se estabelecem na sala de aula. Contudo, uma indagação se impõe: é possível considerar o diálogo-com-mídias como um diálogo, na forma em que Alrø e Skovsmose (2010) apresentam essa noção? Lembramos que para ser considerada como um diálogo, uma conversação deve sustentar determinadas características, a saber: realizar uma investigação, correr riscos e promover a igualdade.

Desde a escolha do tema, as interações entre os alunos sugerem uma disposição para realizar uma investigação a respeito do assunto escolhido, ao demonstrarem intenções de abandonar a comodidade das certezas e se deixarem levar pela curiosidade a respeito dos preços das viagens.

Ao explorarem as perspectivas dos demais participantes, principalmente da mídia internet, os alunos abriram mão da certeza inicial de que a passagem de avião é sempre mais barata que a de ônibus, assumindo uma nova maneira de comparar os valores dessas passagens, na qual a 'variável data da compra' passou a ser considerada. Essa abertura a novos pontos de vistas e convicções, sugerem disposição a correr riscos, de acordo com nossa leitura.

Essa disposição aos riscos está associada à imprevisibilidade dos rumos que a investigação pode tomar, quando pré-concepções e certezas são deixadas de lado no fluxo do processo investigativo. Quando o professor mediador convidou os alunos a buscarem e compararem os preços das passagens na internet, não havia como antever para onde a investigação os conduziria. Podemos imaginar cenários possíveis. Os alunos poderiam, por exemplo, se negar a buscar por esses valores e se refugiarem na certeza de que ir de avião é sempre mais barato que de ônibus. Outra possiblidade, seria os alunos indagarem a respeito de 
quem estava vendendo as passagens no site, o que conduziria os processos investigativos na direção de perceber a Matemática em ação que está oculta no sistema de vendas de passagens online. Tal possibilidade, asseveramos, estaria de acordo com as preocupações da Educação Matemática Crítica.

No que se refere à participação da mídia internet, entendemos que o próprio uso educacional do site, projetado, a princípio, para a compra e a venda de passagens online, pode ser visto como uma mudança nos pontos de vistas dessa mídia para que ela pudesse tomar parte na investigação. Além disso, a própria perspectiva defendida pelos alunos a respeito do menor preço da passagem de avião, em relação à de ônibus pode ser vista, também, como o ponto de vista defendido pela internet na metáfora do diálogo-com-mídias, através das listas de preços impressas referentes ao segundo episódio. Destacamos que essa perspectiva da mídia também mudou ao longo da investigação.

Contudo, é importante destacarmos que os pontos de vista da internet no diálogo-commídias integram uma metáfora. Só faz sentido falar nas intencionalidades e convicções das mídias, a partir das interpretações que os atores humanos envolvidos na investigação fazem delas. Nessa linha de pensamento, destacamos que na medida em que as perspectivas dos alunos a respeito dos valores das passagens aéreas e rodoviárias mudaram mediante o ponto de vista da internet, mudaram também as interpretações desses atores humanos a respeito das convicções dessa mídia. Ao interpretarmos a noção de diálogo-com-mídias dessa maneira, passa a fazer sentido falar nos pontos de vistas defendidos pelas mídias.

Conjecturamos que se promoveu equidade entre os atores humanos e tecnológicos nesse diálogo-com-mídias. A própria moldagem recíproca dos pontos de vistas entre alunos e internet sugere isso. Além disso, o padrão do diálogo que se estabelece na tradição do autoritarismo burocrático da sala de aula de Matemática, e que ganhou uma versão digital com a ação da internet no segundo episódio, diluiu-se ao longo da investigação e no transcorrer do diálogocom-mídias.

Ao considerarmos a possibilidade de um diálogo entre humanos e mídias, a partir da metáfora do diálogo-com-mídias, como ocorrido no $3^{\circ}$ Episódio, buscamos aproximar a visão de conhecimento assumida pelo construto teórico seres-humanos-com-mídias, na qual as mídias adquirem poder de ação nos coletivos que produzem conhecimento, com a noção de aprendizagem como diálogo, presente na perspectiva da Educação Matemática Crítica.

Tangram - Revista de Educação Matemática, Dourados - MS - v.1 n. 1, pp. 18 - 36 (2018) 
Nesse sentido, pensamos no diálogo-com-mídias em termos de um diálogo possível entre essas duas perspectivas teóricas, o que pode ser considerado, também, em termos de uma moldagem recíproca entre essas visões.

Como resultado central de nossa investigação, concluímos que a visão de aprendizagem como diálogo pode moldar a concepção epistemológica do construto seres-humanos-commídias, ao incluir características de diálogo às interações entre atores humanos e mídias. Analogamente, o poder de ação conferido às mídias na perspectiva dos seres-humanos-commídias pode também moldar a concepção de aprendizagem como diálogo, ao considerar os pontos de vistas e intenções desses atores não humanos nos processos dialógicos, como revelam nossos dados.

\section{Considerações finais}

Ao longo do presente artigo, procuramos apresentar a incipiente noção de diálogo-commídias, tomando como pano de fundo as interações comunicativas estabelecidas entre alunos, professor e mídias, ao longo de episódios que ocorreram durante o um Projeto de Modelagem desenvolvido com alunos do sexto ano do Ensino Fundamental.

Tomamos como ponto de partida, as implicações pedagógicas dos Projetos de Modelagem, no sentido de favorecer a ocorrência de cenários para a investigação e interações comunicativas, pautadas na noção de diálogo, e nossa visão de conhecimento assumida perante o construto Seres-humanos-com-mídias. Da sintonia entre essa e aquelas emergiu a possibilidade de considerar a ação das mídias nos processos comunicativos, em termos das características presentes na noção de diálogo.

Ao dar voz às mídias nos processos comunicativos, a noção de diálogo-com-mídias busca uma aproximação conceitual entre a visão de conhecimento, posta no construto teórico Seres-humanos-com-mídias, e a noção de diálogo e aprendizagem, presentes na Educação Matemática Crítica. Entendemos que a aproximação entre essas duas perspectivas teóricas conduz a uma moldagem recíproca dessas concepções.

Nesse sentido, conforme apresentados nos episódios anteriores, as interações entre humanos e mídias, segundo a visão dos seres-humanos-com-mídias, passam a ser vistas com características de diálogo, ao passo em que a noção de diálogo passa a considerar o poder de 
ação das mídias, possibilitando aos participantes aprenderem e modificarem suas opiniões e decisões.

Vale enfatizar que, ao buscarmos essa aproximação conceitual entre duas perspectivas teóricas consagradas, no contexto das pesquisas em Educação Matemática, falamos na mesma direção que Alrø e Skovsmose (2010), ao sugerirem que a participação das mídias deve ser levada em conta na noção de diálogo (c. f. Skovsmose, 2007).

Contudo, salientamos que a noção de diálogo-com-mídias pode aprofundar essa possibilidade ao considerarmos as intencionalidades e perspectivas desses atores não humanos nos processos dialógicos. Lembramos, todavia, que essas intenções e perspectivas atribuídas às mídias, só ganham sentido na maneira como os atores humanos as interpretam, em moldagem recíproca com suas próprias intencionalidades e perspectivas.

Por outro lado, é importante destacar que a incipiente noção de diálogo-com-mídias, que busca um encontro entre a visão de conhecimento dos Seres-humanos-com-mídias e a concepção de diálogo, sugere a necessidade de novas investigações nesse mesmo viés, para "que se desenvolvam parâmetros que possam dar conta da avaliação das investigações por ela mesma produzida, com critérios reguladores claros e públicos” (Garnica, 2001, p. 39-40).

Enfim, defendemos que o encontro possível entre essas duas perspectivas teóricas, promovido no entendimento da incipiente noção de diálogo-com-mídias, busca estabelecer um diálogo entre essas próprias concepções de conhecimento e aprendizagem. Da mesma maneira que acontece nas metafóricas conversas entre humanos e mídias, apresentadas na seção anterior, a comunicação proposta entre essas duas perspectivas teóricas caminha no sentido de incluir aspectos de diálogo, a recordar: realizar uma investigação; correr riscos e promover a igualdade.

Nesse sentido, realizar uma investigação aponta para as sendas de pesquisas que se abrem mediante à incipiente noção de diálogo-com-mídias. Correr riscos diz respeito às próprias reconfigurações que esse diálogo entre concepções teóricas pode promover no escopo dessas próprias teorizações, no decurso das futuras investigações. Promover a igualdade nos leva a considerar posturas investigativas que não busquem sobrepor uma perspectiva teórica à outra, no sentido de vencer uma discussão, mas que se proponham a explorar todas as possibilidades que emergem desse encontro.

Por fim, esperamos que as ações narradas neste artigo, resultante de uma pesquisa de mestrado profissional, possam convidar os professores a arriscarem em suas práticas, buscando desvencilhar-se da permanente zona de conforto. Nesse desvencilhamento, o professor 
descentra-se e passar a mediar as ações com os discentes, constituindo uma zona de risco em que as mídias, a internet e materiais que os alunos possam trazer para a investigação auxiliem no estabelecimento de diálogos promovedores de conhecimentos legítimos.

\section{Referências}

Alrø, H.; Skovsmose, O.(2010) Diálogo e aprendizagem em educação matemática. $2^{\mathrm{a}}$. ed. Tradução Orlando Figueiredo. Belo Horizonte: Autêntica Editora.

Araújo, J. L. (2010) Brazilian research on modelling in mathematics education. ZDM Mathematics Education. 42:337-348. DOI 10.1007/s11858-010-0238-9.

(2002) Cálculo, tecnologias e modelagem matemática: as discussões dos alunos. 2002. 173f. Tese (Doutorado em Educação Matemática) - Instituto de Geociências e Ciências Exatas, Universidade Estadual Paulista, Rio Claro.

Bogdan, R.; Biklen, S.(1994) Investigação qualitativa em Educação: fundamentos, métodos e técnicas. In: Investigação qualitativa em educação. Portugal: Porto Editora. P. 1580 .

Borba, M. C.; Villarreal, M. E. (2005) Humans-With-Media and the Reorganization of Mathematical Thinking: information and communication technologies, modeling, experimentation and visualization. v. 39, New York: Springer.

Canedo JR., N. R. (2014) A modelagem como uma "atividade" de "seres-humanos-commídias”. 2014. 238f. Dissertação (Mestrado Profissional em Educação Matemática) Universidade Federal de Juiz de Fora. Instituto de Ciências Exatas. Programa de pós-graduação em Educação Matemática, Juiz de Fora.

Garnica, A. V. M. (2001) Pesquisa qualitativa e Educação (Matemática): de regulações, regulamentos, tempos e depoimentos. Mimesis. Bauru, v. 22, n. 1, p. 35-48.

Skovsmose, O. (2000) Cenários para investigação. BOLEMA. Rio Claro (SP). v. 13, n. 14, p. 66-91.

(2007) Educação Crítica: incerteza, matemática, responsabilidade. Tradução Maria Aparecida Viggiani Bicudo. São Paulo: Cortez.

Recebido: 15/01/2018

Aprovado: 06/03/2018 